\title{
USO DO MERCÚRIO E REFLEXOS SOCIOAMBIENTAIS NO GARIMPO DE CAXIAS, MUNICÍPIO DE LUÍS DOMINGUES-MA
}

\author{
Lílian Daniele Pantoja Gonçalves $^{(\mathrm{a})}$, José Fernando Rodrigues Bezerra ${ }^{(\mathrm{b})}$ \\ (a) Aluna do PPGEO/Universidade Estadual do Maranhão- UEMA, E-mail:danielepantoja@ hotmail.com \\ (b) Prof ${ }^{\circ}$ Dr. do Departamento de História e Geografia da Universidade Estadual do Maranhão- UEMA/ E-mail: \\ fernangeo@yahoo.com.br
}

Eixo: Uso e ocupação das terras e legislação ambiental

\begin{abstract}
Resumo
A atividade de mineração é imprescindível para o desenvolvimento das sociedades e da economia em seus mais diversos setores produtivos, sendo, ao longo dos anos, um dos sustentáculos econômico e político. Porém, os impactos causados pela mineração, vêm onerando o ambiente drasticamente, sobretudo o uso de produtos, como o mercúrio. Neste sentido, a pesquisa analisa os problemas ambientais e sociais provenientes da extração mineral sobretudo ao uso do mercúrio no Garimpo de Caxias, localizado no Município de Luís Domingues- MA, porção noroeste do Estado do Maranhão. A pesquisa propôs metodologia baseada no Geossistema, afim de diagnosticar as consequências dessa atividade nos meios físico, biótico e antrópico. Diante dos estudos, concluiu-se que os moldes de produção investigados, proporciona pouquíssimo aspectos positivos (atividade fim de sobrevivência do garimpeiro, remuneração), têm fomentado impactos socioambientais negativos, os quais constituem para um cenário instável ameaçando o bem estar social e equilíbrio do ambiente local.
\end{abstract}

Palavras chave: Garimpo de Caxias; Mercúrio; Reflexos socioambientais.

\section{Introdução}

$\mathrm{O}$ ato de minerar é uma das atividades mais primitivas exercidas pelo homem como fonte de sobrevivência e produção, através da manipulação de rochas e minerais para a produção de artefatos que facilitassem a vida em sociedade, especialmente pela possibilidade da produção de bens e acumulação de capital.

Segundo Ramos (2005), a interferência do homem na natureza com a finalidade de exploração dos recursos naturais gera problemas ambientais, onde o solo e a água são os primeiros recursos afetados. Essas áreas podem ser inutilizadas caso haja teores de elementos-traço acima do estipulado pelas legislações em vigor, sendo que esses podem permanecer no ambiente por um longo período. 
Neste sentido, a atividade extrativa decorrente da mineração, têm causado por suas práticas sem técnicas adequadas e sem controle um visível quadro de degradação no ambiente (FERNANDES; ALAMINO, 2014).

A descoberta de ouro na porção norte do Estado do Maranhão, região localizada entre os rios Gurupi e Maracaçumé, remonta ao ano de 1624, com as primeiras incursões de aventureiros europeus em território brasileiro. Segundo relatos da época os primitivos índios que viviam na região já conheciam o metal considerando-o, todavia, de pouca importância.

Porém, um fator agravante na extração do ouro, se dá através da poluição mercurial, decorrente da atividade garimpeira, a qual tem sido objeto de estudos no Brasil e no mundo. A atividade extrativa mineral altera o meio ambiente, tornando-se fonte de degradação, quando empreendida sem as medidas de controle adequadas.

O mercúrio metálico lançado no meio ambiente, é volátil, podendo ser oxidado e metilado para a forma mais tóxica, o metil-mercúrio, incorporando-se aos organismos vivos pela cadeia alimentar. Dessa forma, pode ocasionar sérios danos à saúde dos animais e do ser humano (TANNÚS, 2001).

Assim, no processo de garimpagem na área de estudo, a utilização do mercúrio pelos garimpeiros para concentração do ouro na bateia é um procedimento quase que inevitável. Geralmente utilizam o composto orgânico do mercúrio no formato Metilmercúrio $\left[\mathrm{CH}_{3} \mathrm{Hg}\right]^{+}$, este é considerado o mais importante devido à alta toxicidade para o organismo humano. Além do uso indiscriminado de mercúrio, observa-se que o mau uso da terra também pode aumentar os níveis de metilação do mercúrio, assim como o escoamento superficial pode transportar o mercúrio para corpos d'água locais e contaminar o lençol freático. Fatores, tais como, $\mathrm{pH}$, condutividade elétrica, disponibilidade de oxigênio, temperatura, atividade biológica e concentração de nutrientes, entre outros.

Desta forma, o risco de contaminação do ambiente por mercúrio, em área de garimpo, tem sido alvo de preocupação da pesquisa, no intuito de verificar a quantidade de teor de mercúrio lançado nos efluentes do garimpo, o que permeia por uma questão de saúde pública. Sendo portanto, um dos procedimentos da pesquisa, a coleta de amostras de água superficial em dois lagos do garimpo (antigos barrancos) e água consumida pela comunidade para fim de análise físico-química e identificar o teor de mercúrio. 


\section{1 Área de Estudo}

28 de Junho à 02 de Julho de 2017

O garimpo de Caxias, está localizado a $8 \mathrm{~km}$ da sede do município de Luís Domingues - MA, na porção noroeste do Estado. O acesso à comunidade do garimpo é servida por acesso da rodovia - MA 301 entrando em estrada vicinal de chão batido. A pequena comunidade do garimpo do Caxias, está instalada em uma propriedade que inicialmente era particular e hoje apresenta-se como povoado de Luís Domingues. A comunidade do Caxias é composta por 21 casas, uma escola -creche comunitária, e uma igreja evangélica.

Segundo relatos de moradores, a potencialidade aurífera do garimpo de Caxias foi identificada em 1934, iniciando-se o processo de exploração incipiente. Inicialmente os garimpeiros tinham acesso aos barrancos, e todo o trabalho era executado manualmente. Segundo relato do mais antigo morador da área, os instrumentos comumente usados neste período eram: pilão de ferro, pesando aproximadamente $200 \mathrm{~kg}$, e a bateia. Desde então, o garimpo de Caxias é exercido de forma manual e na contramão da legislação vigente, ou seja, vem atuando ao longo dos anos de forma clandestina, com uma produção que utiliza métodos artesanais para extração do ouro. Porém, mesmo com tais especificades, têm sua importância no sentido de fomentar a economia local e até regional.

O objetivo deste trabalho é trazer informações sobre a atividade de extração de ouro no garimpo de Caxias e os reflexos ao ambiente e à saúde humana decorrentes da utilização do mercúrio. Estudos dessa natureza possibilitam compreender as relações entre meio ambiente e saúde pública, possibilitando o desenvolvimento de novas medidas de prevenção e controle ambiental.

\section{Material e Métodos}

A pesquisa foi realizada nos meses de maio a novembro de 2016, conduzida metodologicamente, com base na abordagem da Teoria do Geossistema, na perspectiva de Bertrand (1968), o qual entende o geossistema como uma estrutura dinâmica resultante da interação entre o potencial ecológico, a exploração biológica e a ação antrópica, sendo que todos esses componentes se inter-relacionam e influenciam o funcionamento dos geossistemas. No garimpo do Caxias esses três eixos estão interligados, devido a atuação e a atividade do homem na área. A pesquisa teve como ponto de partida, levantamento e análise do material bibliográfico apoiado em autores como: Ramos (2005), Tannus (2001), Jacobi (2006); Fernandes; Alamino; Araujo (2014) e material cartográfico relacionado com o tema e a área objeto de estudo, realizados na bibliotecas da Universidade Estadual do Maranhão - UEMA, Departamento Nacional de Produção Mineral (DNPM) - MA, estudo das Resoluções do CONAMA relacionadas ao meio 


\section{OS DESAFIOS DA GEOGRAFIA FÍSICA NA FRONTEIRA DO CONHECIMENTO \\ Instituto de Geociências - Unicamp \\ Campinas - SP \\ 28 de Junho à 02 de Julho de 2017}

ambiente no setor mineral, dentre outros procedimentos, como: Trabalho de Campo com o auxílio do GPS, Câmera Digital, e observações quanto ao trabalho realizado pelos garimpeiros.

Em consonância com os trabalhos de campo possibilitou-se a definição das questões norteadoras que contribuíram na elaboração de questionários com perguntas semiestruturadas. Foram elaborados questionários distintos, sendo destinados aos garimpeiros e liderança comunitária, o qual contemplou perguntas considerando a questão social, percepção ambiental, uso do mercúrio, produção de ouro, organização de trabalho desses garimpeiros. $\mathrm{Na}$ área de estudo, 40 garimpeiros trabalham diariamente, sendo que a abrangência das entrevistas foi de $15 \%$ do montante total. Nesta etapa de registro de entrevistas locais foram utilizados recurso do rádio gravador portátil.

Quanto a identificação do teor de mercúrio nos corpos líquidos superficiais do garimpo, as coletas de amostras basearam-se pelo método da Agência Nacional das Águas- ANA (2011, p.53), onde foram observados e anotados fatos que poderiam interferir nas características da amostra (cor, odor, ou aspecto estranho como presença de óleos e material sobrenadante), obedecendo os cuidados elencados na metodologia.

Desta forma, os locais de coleta foram escolhidos de acordo com a localização estratégica e uso de água dos lagos, formados por antigos barrancos de mineração. Assim, foram coletadas 05 amostras de águas dos lagos minerados e 01 do poço comunitário, as coletas foram divididas em 03 grupos. (Figura 1). $\mathrm{O}$ Grupo 1- Lago Principal:- Coleta 1A: a 04 metros da margem direita com profundidade de 01m. - Coleta 1B: a $03 \mathrm{~m}$ da margem esquerda com profundidade de $0,70 \mathrm{~cm}$ a $1 \mathrm{~m}$. Grupo 2 - Represa de água de barranco Coleta 2A: $04 \mathrm{~m}$ da margem esquerda, profundidade de 2m. Coleta 2B: próximo a lavagem dos tapetes e caixa d’água- $02 \mathrm{~m}$ da margem direita, com profundidade de $2 \mathrm{~m}$. Grupo 03 - Água de torneirapoço comunitário. Coleta 3A- 01 amostra coletada de água corrente da casa de moradora em frente aos barrancos. 

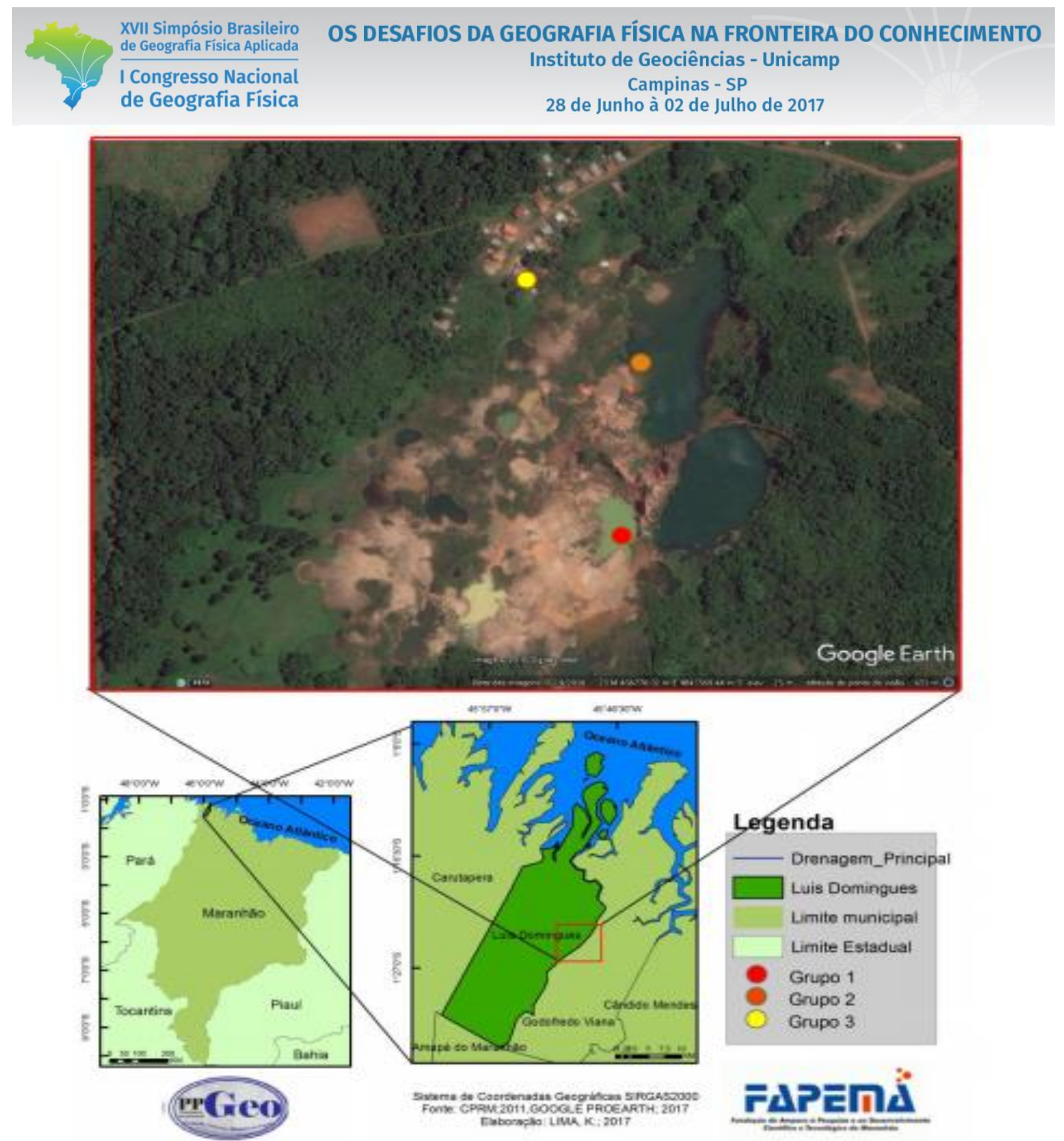

FIGURA 1: Mapa de localização dos pontos de coleta de amostras de água.

As amostras foram coletadas sem a presença de chuva nas últimas 24 horas, de forma manual com o auxílio de uma haste coletora já acoplado em garrafa de polietileno (PET) capacidade para $500 \mathrm{~mL}$. As garrafas estavam devidamente etiquetadas, tampadas e previamente descontaminadas com água destilada e ambientados com água do próprio local de coleta. Para fins de preservar as amostras, as mesmas foram mantidas sob resfriamento em gelo, em caixas térmicas, até chegada ao laboratório, onde foram acondicionadas em geladeira a $4^{\circ} \mathrm{C}$ e, posteriormente, encaminhadas para análise (ANA, 2011, p.55). 
Em laboratório, as análises de mercúrio total, foram realizados pelo Espectrofotômetro de absorção Atômica, de acordo com a metodologia citada em Lutz 2008.

As demais informações coletadas nos trabalhos de campo, foram posteriormente analisados e interpretados seus dados. Desta forma, o registro da atividade de exploração do mineral, permitiu através das pesquisas de campo, uma análise estruturada dos meios físico, biótico e antrópico, que serão detalhados a seguir.

\section{Resultados e discussão}

A problemática analisada neste trabalho abrange os reflexos e problemas sociais e ambientais atribuídos à mineração exercida no garimpo de Caxias, bem como o uso indiscriminado do mercúrio pelos garimpeiros durante o processo de mineração.

No Brasil, durante últimas três décadas do século XX, como ficou conhecida historicamente a chamada "corrida do ouro" estima-se que cerca de 4.000 toneladas de $\mathrm{Hg}$ foram liberadas para o meio ambiente, sendo cerca de 60\% em rejeitos sólidos de mineração Lacerda (2008, apud BRASIL, 2013, p.43).

Na região Noroeste do estado do Maranhão, mas especificamente no Garimpo de Caxias, segundo relatos de moradores antigos, a área rica de minério foi descoberta desde 1934, mas, somente na década de 1980, a disseminação da notícia de que havia grande quantidade de ouro no garimpo atraiu grande contingente de imigrantes para a área, fazendo com que os garimpeiros se fixassem no local construindo casebres até hoje ocupados por moradores que presenciaram a formação deste garimpo, e a partir daí a extração do ouro era realizado com o emprego de tecnologia rudimentar como motores e bombas para a lavagem do cascalho e seleção do material. Essa "facilidade" de exploração do ouro resultou em maior produtividade e tornou a área muito mais atrativa. Sua atividade nunca foi legalizada e portanto atua clandestinamente.

\subsection{Garimpo de Caxias e uso de Mercúrio}

Os primeiros estudos realizados na área do garimpo, revelaram áreas degradadas pela extração de ouro, devido intensa atividade de exploração desde os anos 80, resultando em seus corpos líquidos expressiva quantidade de metilmercúrio e consequentemente nos sedimentos, decorrente do último intenso ciclo garimpeiro. Nessa ocasião, um contingente numeroso de homens empreendeu um intenso trabalho, utilizando equipamentos, como bombas de sucção, calhas de concentração. Todo esse período de exploração, assim como hoje, o mercúrio foi e ainda é usado indiscriminadamente.

No processo de extração do minério, o mercúrio é utilizado para auxiliar na separação do ouro, pelo processo da "amalgamação" em que o mercúrio adere ao ouro formando o amálgama. 


\section{OS DESAFIOS DA GEOGRAFIA FÍSICA NA FRONTEIRA DO CONHECIMENTO \\ Instituto de Geociências - Unicamp \\ Campinas - SP \\ 28 de Junho à 02 de Julho de 2017}

A prática artesanal exercida pelos garimpeiros no garimpo de Caxias, implica na utilização do mercúrio na sua forma líquida, fato este comprovado durante a aplicação dos questionários, onde todos os entrevistados responderam de forma categórica que utilizam o elemento, o uso dá-se uma vez por semana, com a abertura da caixa de sedimentos onde os mesmos denominam de "cobra fumando". Tal equipamento é extramente rudimentar e feito com tábuas e assoalhado com um "carpete" grosso para deter os sedimentos e partículas de ouro. Desta forma, a caixa é aberta uma vez por semana, geralmente aos sábados e com o uso do mercúrio as partículas de ouro são aprisionadas. Assim, cada barranco possui suas máquinas com motor onde ocorre todos os procedimentos de garimpagem artesanal.

Além disso, durante as entrevistas realizadas muitos garimpeiros relataram que estão na atividade como forma de sobrevivência, já que não há outra oportunidade de emprego na região, muitos denominam-se até agricultores e garimpeiros, uma vez que as duas atividades dão proventos e subsistência para suas famílias. Porém, o desejo de ingressar e de terem oportunidade de estudar e se qualificar, seria uma entrada para mudanças e novas perspectivas para suas vidas.

Com relação a quantidade de mercúrio utilizado por barranco semanalmente, $75 \%$ dos garimpeiros responderam que utilizam 50 gramas do elemento, as demais porcentagens registraram uma quantidade menor quanto ao uso do elemento, entre 20 e 30 gramas.

O resultado das análises comprovaram que em algumas amostras de água dos lagos há ocorrência de mercúrio com um teor acima de $0,2 \mathrm{mg} / 1(0,2 \mathrm{ppm}=200 \mathrm{ppb})$, limite que indica um valor acima do permitido conforme Resolução CONAMA 357/05, que trata de níveis máximos da qualidade das águas superficiais, águas doces - classe 2. Com exceção da amostra $1 b$ do lago principal e da água do poço que

a comunidade utiliza, onde os valores do teor de mercúrio ficaram abaixo, ou seja tolerante, obedecendo a Resolução CONAMA. (Tabela I). 
Tabela I: Concentração de mercúrio dos corpos líquidos superficiais- Garimpo de Caxias - MA

\begin{tabular}{|c|c|c|c|}
\hline $\begin{array}{l}\text { GRUPO DE } \\
\text { AMOSTRAS } \\
\end{array}$ & COLETA & $\begin{array}{l}\text { LIMITE DE } \\
\text { DETECÇÃO }\end{array}$ & $\begin{array}{l}\text { CONCENTRAÇÃO } \\
\text { DE } H g(\mathrm{mg} / \mathrm{L})\end{array}$ \\
\hline \multirow{3}{*}{ Grupo 01} & Coleta 1A -Lago principal- margem direita & $>\mathrm{LD}$ & 0,2092 \\
\hline & & & \\
\hline & $\begin{array}{c}\text { Coleta 1B- Lago principal -margem } \\
\text { esquerda }\end{array}$ & $<\mathrm{LD}$ & 0,016 \\
\hline \multirow[t]{2}{*}{ Grupo 02} & Coleta 2A- Lago 02- margem esquerda & $>\mathrm{LD}$ & 0,232 \\
\hline & $\begin{array}{l}\text { Coleta } 2 \mathrm{~B} \text { - Lago } 02-\text { margem direita } \\
\text { próximo a lavagem de tapetes e caixa dágua }\end{array}$ & $>\mathrm{LD}$ & 0,267 \\
\hline Grupo 03 & $\begin{array}{l}\text { Coleta 1A- Água corrente da comunidade- } \\
\text { casa em frente aos barrancos }\end{array}$ & $<\mathrm{LD}$ & 0,00258 \\
\hline
\end{tabular}

Destaca-se ainda, o fator agravante facilitador de contaminação dos garimpeiros pelo mercúrio, pela falta de equipamentos de proteção, como máscaras ou luvas, permitindo que o mercúrio seja diretamente inalado pelos garimpeiros, os quais são conscientes do risco e o medo de ao longo do tempo serem acometidos de sérias complicações de saúde.

\subsection{Reflexos socioambientais garimpo de Caxias}

Diante dos problemas relacionados acima, conclui-se que a extração mineral realizada no garimpo de Caxias, possibilita reflexos ou problemas socioambientais, a saber:

- Meio Físico: o decapeamento da vegetação reduz a biodiversidade; a mineração modifica a paisagem e reduz a disponibilidade de recursos minerais; o desmonte de solo e rochas são feitos com bombas que trazem jatos de água, desmoronando de forma provocada os barrancos, e a grande revirada de terra na área causando uma mudança no ambiente minerado (Figura 2 ). 


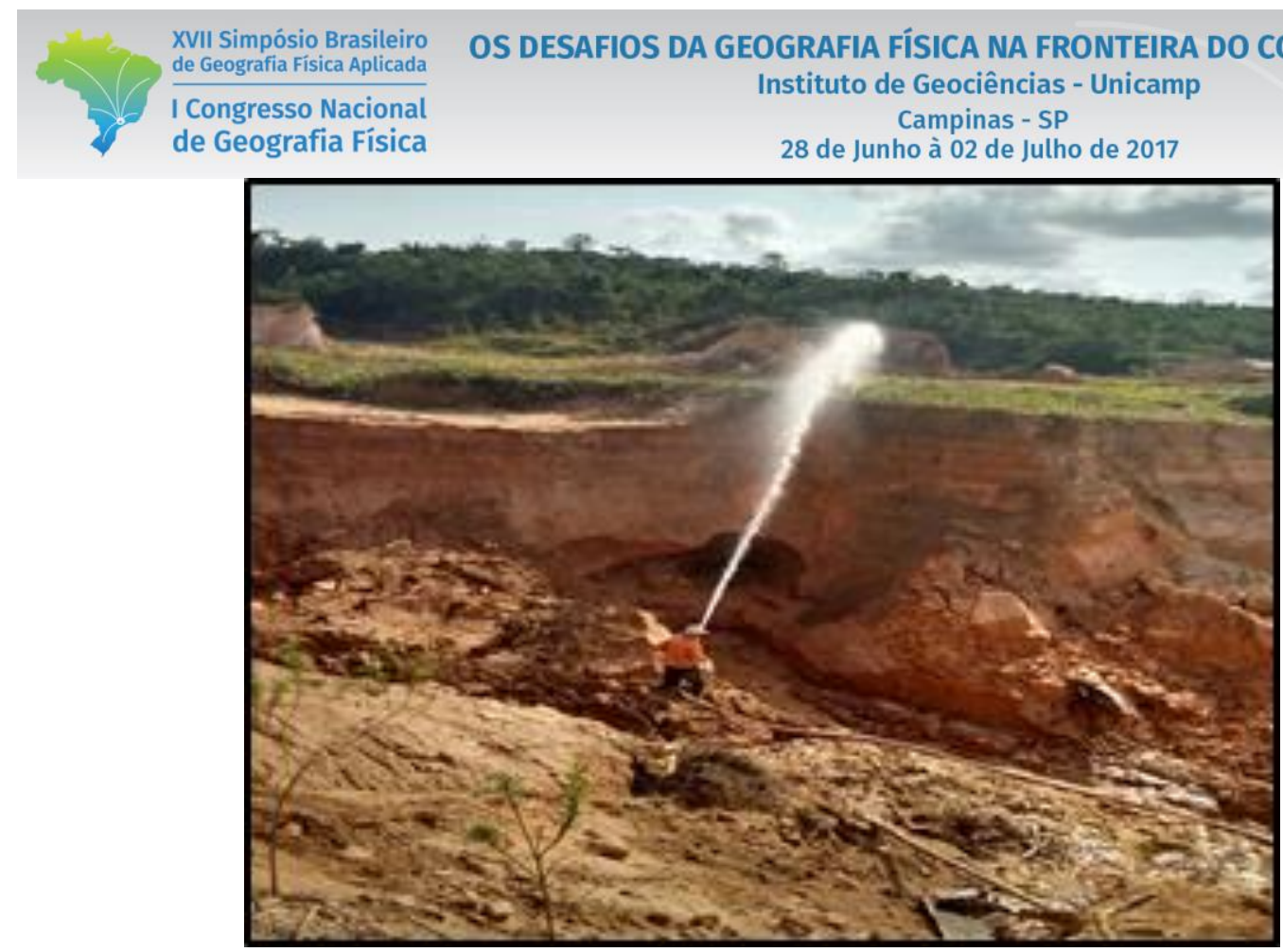

Figura 2- Atividade de garimpagem- desmoronamento de barranco

- Meio Biótico: Neste meio percebe-se a ausência de animais e aves, pois a presença humana e os ruídos e barulho dos motores nos barrancos condicionam a migração de aves e mamíferos, e o ato de minerar na área chega a causar interferências na morfologia dos vegetais provocando ainda, degradação visual da paisagem (Figura 3 e 4 ).

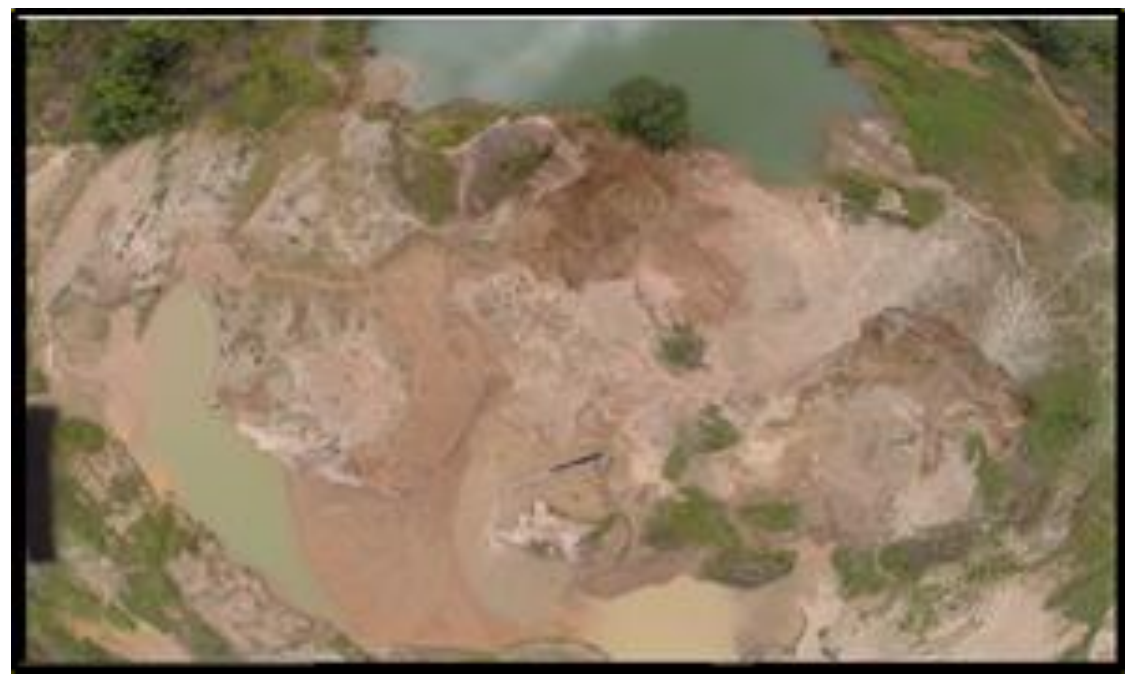

Figura 3- Deterioração ambiental e mudança da paisagem 

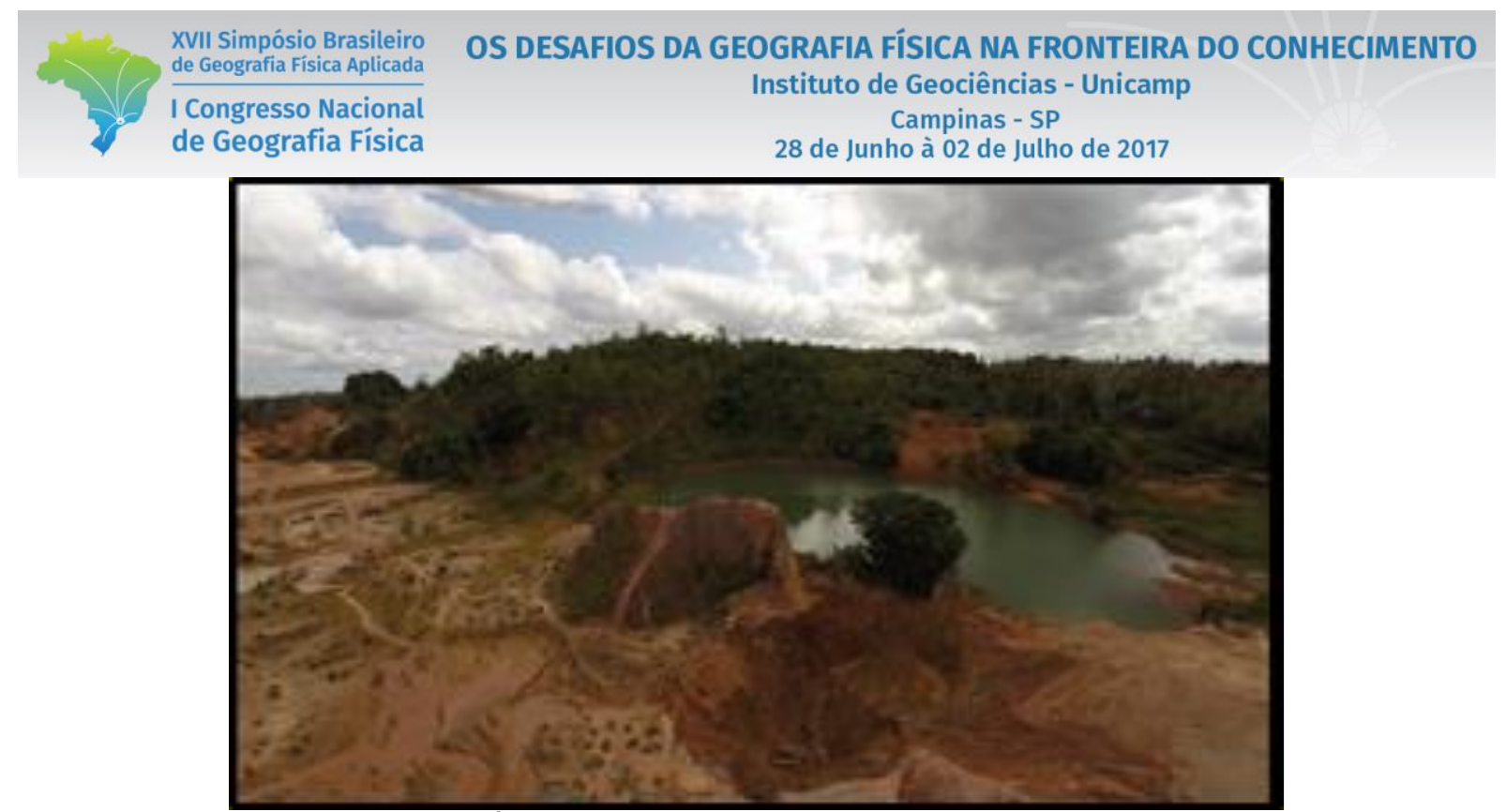

Figura 4- Área minerada e reflexos na mudança da paisagem.

- Meio Antrópico: para o meio antrópico, foram identificados impactos positivos e negativos. Os positivos estão ligados à geração de emprego e renda, o que possibilita uma oportunidade para a sobrevivência de trabalhadores garimpeiros e suas famílias, mesmo que tal atividade realizada no garimpo seja exercida como informal e de forma clandestina. Quanto aos impactos negativos, pôde-se diagnosticar: a) condições insalubres de trabalho (figura 5 e 6), uma vez que estão expostos ao sol, a água, poeira e contato sem nenhuma precaução com o mercúrio; b) o uso de mercúrio na atividade expõe trabalhadores a grandes riscos de saúde; c) Risco de morte por desmoronamento de barrancos.

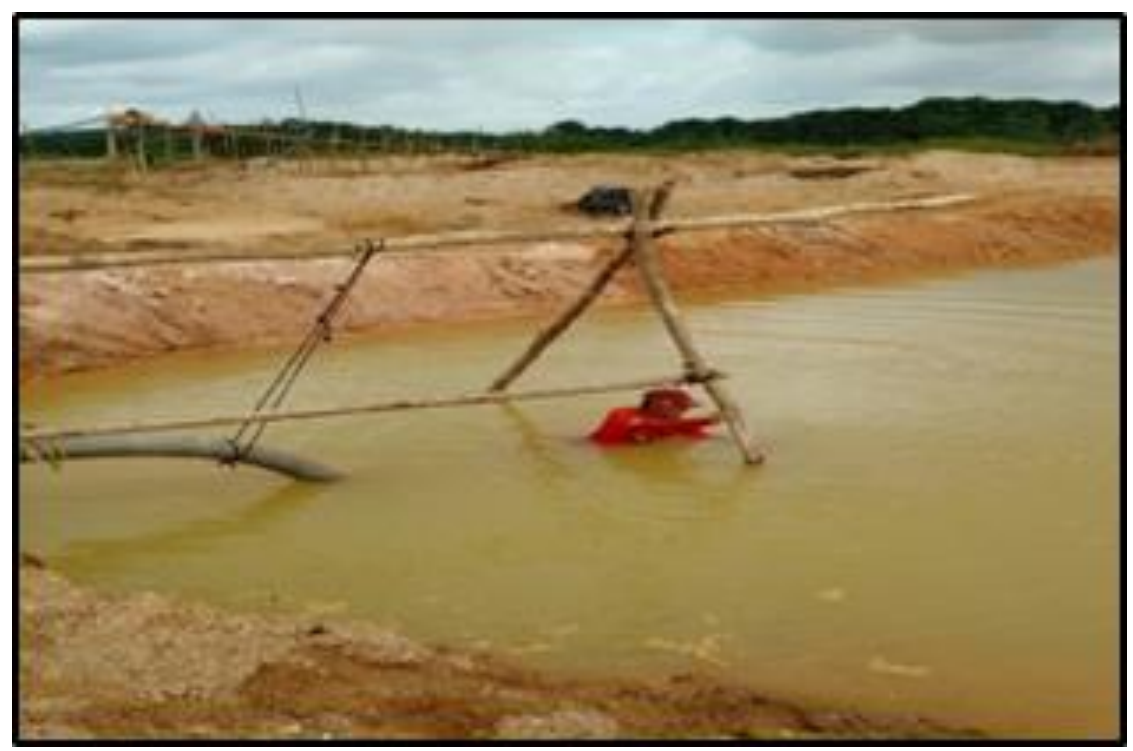

Figura 5- Trabalhador em condição insalubre de trabalho. 


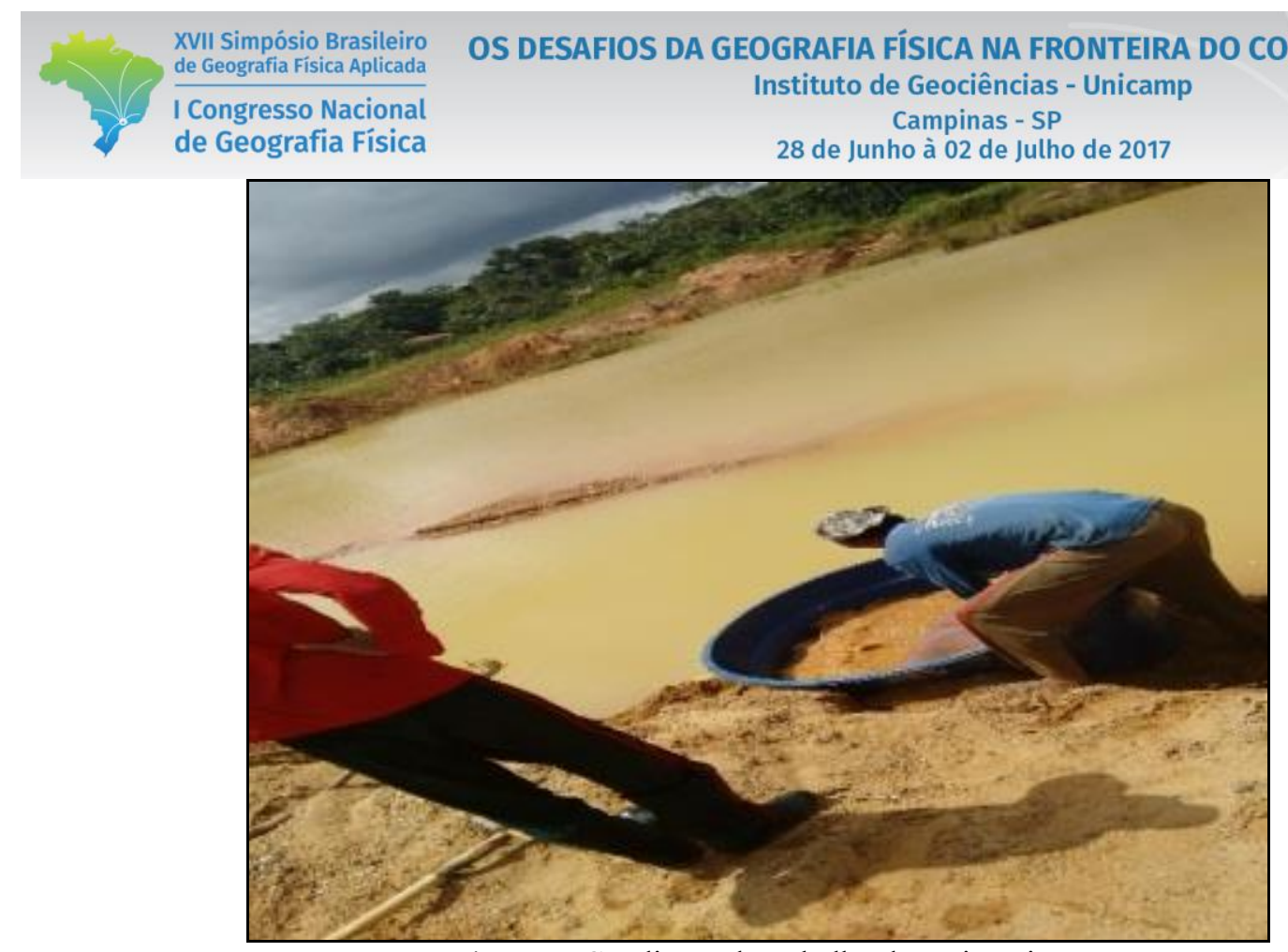

Figura 6- Condições de trabalho de garimpeiro

Nota-se que os reflexos da degradação ambiental em áreas de garimpo podem ser observados no conjunto da paisagem e em todos os seus elementos como o solo, fauna, flora e na geomorfologia. Assim, as mudanças que ocorrem no meio físico geram grande impacto no ambiente minerado.

Por fim, conhecendo-se, mesmo que de forma lacônica, os reflexos ou problemas associados às atividades mineradoras as quais impactam o ambiente com sua forma de extração e o uso do mercúrio sem critérios, conclui-se que, por meio de instrumentos de avaliação de impacto e planejamento ambientais, pode-se adotar medidas que evitem ou atenuem os impactos negativos advindos da mineração, reduzindo assim os danos socioambientais e, consequentemente, os custos envolvidos na sua remediação ou correção.

\section{Considerações}

Os impactos ambientais causados pela mineração na área de extração de ouro, implicam, entre outras causas, o desmatamento de áreas verdes, modificação da topografia, contaminação dos corpos líquidos como possivelmente dos garimpeiros. Por ser uma atividade essencial para os garimpeiros, toda a problemática relacionada a esta atividade merece tratamento especial regulamentando sua forma de ação, vigilância continuada e permanente dessas populações, além de se estabelecer as bases para avaliar a resolutividade das medidas preventivas, corretivas e ou mitigadoras.

Nota-se que a área de garimpo sofre diariamente alterações prejudiciais, haja vista que o ato de minerar, tanto no processo de extração mineral quanto no de deposição de rejeitos, modifica a estrutura do terreno, 
o que, a priori, indica a impossibilidade de se reverter o quadro. Em todas as etapas da atividade extrativa, a preservação ambiental deveria vir sempre acompanhada do cuidado com o meio, através de medidas preventivas controlando desta forma, alguns impactos possíveis de ocorrer na área minerada, como: planejamento da retenção do material desagregado; do uso de metais pesados, como o mercúrio, um bom padrão de qualidade da água para consumo humano. Uma vez adotadas essas medidas, os impactos seriam minimizados.

Durante a realização da pesquisa, identificou-se que os garimpeiros e moradores da área têm uma percepção dos principais problemas ambientais ocorridos, dentre eles, os desmatamentos e os desmoronamentos, poluição sonora, e principalmente a questão visual do garimpo, ou seja, a mudança da paisagem e ainda a situação de pobreza em que se encontram. Os garimpeiros e moradores da comunidade se mostraram sensíveis à questão ambiental, são conscientes das consequências da atividade e percebem as alterações negativas no meio ambiente. Mas informaram que não tem outra forma de subsistência e trabalho disponível, e lutam pelo funcionamento diário do garimpo.

Conclui-se que a mineração é uma atividade econômica imprescindível ao desenvolvimento da sociedade, todavia seus efeitos e consequências devem ser analisados de forma minuciosa e ressalvando o bem estar socioambiental. Nesta perspectiva, deve-se propor mecanismos práticos que possibilitem a mitigação dos impactos negativos da mineração, visando um desenvolvimento socialmente justo e que amenizem as alterações ambientais da área.

\section{Agradecimentos}

Ao Programa de Pós-Graduação em Geografia da Universidade Estadual do Maranhão, à Coordenação do Mestrado na pessoa do Prof. Dr. José Fernando Rodrigues Bezerra e à Fundação de Amparo à Pesquisa e Desenvolvimento Científico do Maranhão - FAPEMA, pelo incentivo e suporte necessários para a realização desta pesquisa.

\section{Bibliografia}

BERTRAND, G. Paisagem e geografia física global: esboço metodológico. Cadernos de Ciências da Terra, n. 13, Instituto de Geografia da USP, 1971, 27p.

BRASIL. Ministério do Meio Ambiente. Diagnóstico Preliminar sobre o Mercúrio no Brasil. Brasília, 2013.106p. BRANDÃO, Carlos Jesus [et al.]. Guia nacional de coleta e preservação de amostras: água, sedimento, comunidades aquáticas e efluentes líquidos / Companhia Ambiental do Estado de São Paulo; São Paulo: CETESB; ANA. Brasília:,2011. 
CONAMA, 2005. Resolução na 357, de 17 de março de 2005 Publicada no DOU n n 053, de 18/03/2005, págs. 58-63• Alterada pela Resolução 410/2009 e pela 430/2011 Dispõe sobre a classificação dos corpos de água e diretrizes ambientais para o seu enquadramento, bem como estabelece as condições e padrões de lançamento de efluentes, e dá outras providências.

Instituto Adolfo Lutz. Métodos físico-químicos para análise de alimentos/coordenadores Odair Zenebon, Neus Sadocco Pascuet e Paulo Tiglea - São Paulo: Instituto Adolfo Lutz, 2008 p. 1020.

FERNANDES; Francisco Rego Chaves; ALAMINO, Renata de Carvalho Jimenez; ARAUJO, Eliane Rocha. Recursos minerais e comunidade: impactos humanos, socioambientais e econômicos, Rio de Janeiro: CETEM/MCTI, 2014.

FERREIRA, Aurélio Buarque de Holanda. Dicionário Aurélio Básico da Língua Portuguesa. São Paulo-SP. LTDA. 1990.

RAMOS, W. E. S. Contaminação por mercúrio e arsênio em ribeirões do quadrilátero ferrífero - MG, em área de mineração e atividades garimpeiras. Tese. Viçosa - MG, 122 p. 2005.

LACERDA, L.D. \& MALM, O. Contaminação por mercúrio em ecossistemas aquáticos brasileiros: uma análise das áreas críticas. Estudos Avançados (USP) 22: 173-190. 2008.

LUTZ, Instituto Adolfo. Métodos físico-químicos para análise de alimentos /coordenadores Odair Zenebon, Neus Sadocco Pascuet e Paulo Tiglea -- São Paulo: Instituto Adolfo Lutz, 2008, p. 1020.

TANNÚS, M. B. et. al.. Projeto Paracatu: concepção e resultados preliminares.

Jornada Internacional sobre el Impacto Ambiental del Mercúrio Utilizado por la Mineria Aurífera Artesanal em Iberoamérica. Setembro de 2001. Lima, Peru: CYTED, 2001. 